\title{
Spatiotemporal distributions of Fukushima-derived radionuclides in nearby marine surface sediments
}

\author{
M. Kusakabe, S. Oikawa, H. Takata, and J. Misonoo \\ Marine Ecology Research Institute, Tohwa-Edogawbashi Bldg., 347 Yamabuki-cho, Shinjuku-ku, Tokyo, 162-0801, Japan \\ Correspondence to: M. Kusakabe (kusakabe@kaiseiken.or.jp)
}

Received: 28 December 2012 - Published in Biogeosciences Discuss.: 11 March 2013

Revised: 17 June 2013 - Accepted: 17 June 2013 - Published: 25 July 2013

\begin{abstract}
Spatiotemporal distributions of anthropogenic radionuclides in marine surface sediments off Miyagi, Fukushima, and Ibaraki Prefectures were analyzed on the basis of data collected during the monitoring program launched by the Japanese Ministry of Education, Sports, Science and Technology in 2011 right after the Fukushima Dai-ichi Nuclear Power Plant accident began. Concentrations of ${ }^{137} \mathrm{Cs}$ in the surface sediments varied spatially by two orders of magnitude, from 1.7 to $580 \mathrm{~Bq} \mathrm{kg-dry}{ }^{-1}$, and there was no obvious correlation between ${ }^{137} \mathrm{Cs}$ concentration and the proximity of the sampling location to the accident site. The total inventory of ${ }^{137} \mathrm{Cs}$ accumulated in the upper $3 \mathrm{~cm}$ of surface sediments in the monitoring area was estimated to be $3.78 \times 10^{13} \mathrm{~Bq}$, that is, $0.1-2 \%$ of the total ${ }^{137} \mathrm{Cs}$ flux from the plant to the ocean as a result of the accident (the percentage depends on the model used to estimate the total flux). The spatial variations of ${ }^{137} \mathrm{Cs}$ concentration and inventory depended on two main factors: the ${ }^{137} \mathrm{Cs}$ concentration in the overlying water during the first several months after the accident and the physical characteristics of the sediments (water content and bulk density). The temporal variations of the concentrations of other anthropogenic radionuclides $\left({ }^{90} \mathrm{Sr}\right.$, ${ }^{95} \mathrm{Nb},{ }^{110 \mathrm{~m}} \mathrm{Ag},{ }^{125} \mathrm{Sb},{ }^{129} \mathrm{Te}$, and ${ }^{129 \mathrm{~m}} \mathrm{Te}$ ) in the sediments were also investigated. Activity ratios of these nuclides to ${ }^{137}$ Cs suggest that the nuclides themselves were not homogenized before they were removed from seawater to the sediments.
\end{abstract}

\section{Introduction}

Since 1983, the Marine Ecology Research Institute has been monitoring radioactivity in seawater, sediments, and marine life (e.g., fish, squid) in the coastal areas near nuclear power plants all over Japan under contract with the Japanese Ministry of Education, Sports, Science and Technology (MEXT). During this thirty-year period until $2011,{ }^{137} \mathrm{Cs}$ concentrations in the surface sediments collected from coastal waters off the Fukushima Dai-ichi Nuclear Power Plant (FDNPP) and the neighboring Fukushima Dai-ni Plant had been steadily declining with time owing to radioactive decay and other mechanisms, including vertical mixing of sediments by benthic animals and lateral migration of resuspended sediments (Fig. 1). One striking feature in the figure is data scattering in each year, reflecting the possible variability of sediment characteristics such as grain size. Aoyagi and Igarashi (1999) have shown highly variable natures of the sediments in the waters off Fukushima Prefecture. Their grain sizes are in a wide range from gravel to clay. Other areas in this monitoring should also have similar sediment characteristics.

Damage to the FDNPP caused by the Great East Japan Earthquake and subsequent tsunami on 11 March 2011 resulted in the release of large amounts of radionuclides to the surrounding environment. Radionuclides were introduced into the ocean both directly, by the release of contaminated water from the power plant, and indirectly, through atmospheric deposition. Fluvial transport of radionuclides from the land to the ocean may be another pathway. Immediately after the accident, MEXT launched an intensified monitoring program to investigate the impact of the accident on the waters off Fukushima Prefecture and the contiguous prefectures, Miyagi and Ibaraki.

On the basis of the monitoring data and additional complementary data, we report the distributions and inventories of anthropogenic radionuclides derived from the FDNPP in surface sediments collected from May 2011 to February 2012, 


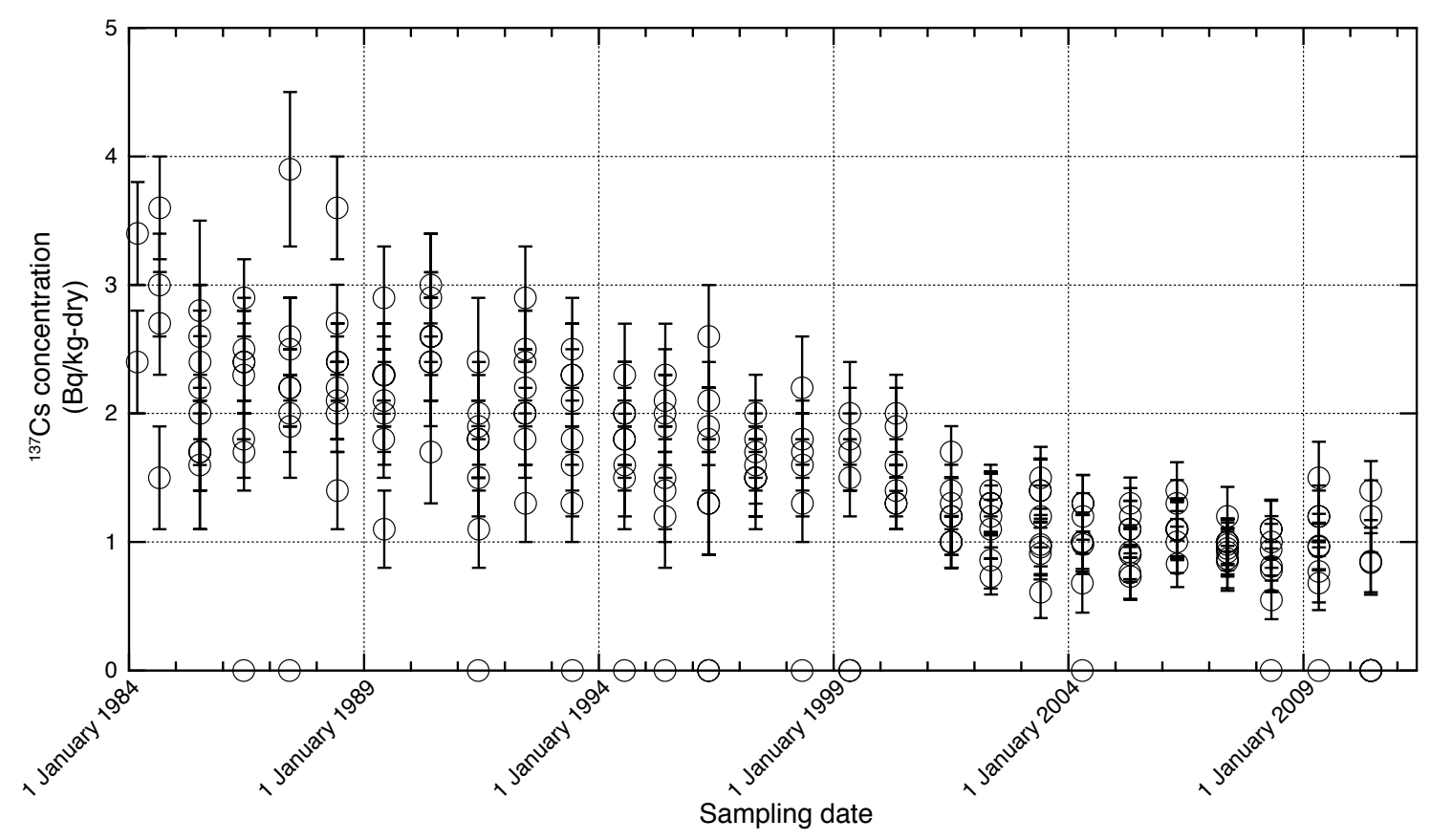

Fig. 1. Temporal variation of ${ }^{137} \mathrm{Cs}$ concentrations in surface sediments collected from the Pacific Ocean off the Fukushima Dai-ichi and Dai-ni Nuclear Power Plants prior to 2011 (1984-2010). The data plotted in the figure were obtained from MEXT (2011). Eight sampling stations were located about $30 \mathrm{~km}$ off the coast. The open circles on the $x$ axis indicate the concentrations were below the detection limit.

and we discuss the mechanism by which the radionuclides were deposited on the sediments.

\section{Materials and methods}

\subsection{Collection of sediment samples}

From May to July 2011, bottom sediment samples were collected on six sampling dates at each of 12 stations (Fig. 2). From September 2011 to February 2012, sediments were collected on four sampling dates from an expanded monitoring area that included the original 12 stations and 18 additional stations (Fig. 2). See Supplementary Table S1 for detailed information about the sampling dates and locations. The sediment samples were retrieved with a multiple corer equipped with eight plastic tubes (opening diameter, $8.2 \mathrm{~cm}$ ), and the upper $3 \mathrm{~cm}$ of the eight sediment cores were combined. Approximately $2 \mathrm{~kg}$ of each combined wet sediment sample was refrigerated immediately on board the sampling vessel for later transport to a laboratory on land for analysis. The remainder of each sample packed in a $120 \mathrm{~mL}$ plastic bottle were saved for measurement of the bulk density and water content of the sediments by a gravimetric method in a laboratory on land. In many cases, two or more sampling casts were necessary to obtain sufficient weight for the analysis.

\subsection{Determination of ${ }^{134} \mathrm{Cs},{ }^{137} \mathrm{Cs},{ }^{131} \mathrm{I}$, and other gamma-ray-emitting nuclides}

The sample was dried at $105^{\circ} \mathrm{C}$ in a laboratory on land. It was then ground in a mortar, sieved through a screen (mesh size, $<2 \mathrm{~mm}$ ), mixed well, and pulverized to a homogeneous powder in a table top grinder. An aliquot of each dried sediment sample (400-600 g) was placed in a plastic container and analyzed by means of nondestructive gamma-ray spectrometry with a variety of coaxial type high purity Ge detectors: they were mainly Canberra GC40195, GX4021, and GC10021 with a relative efficiency of $40 \%, 43 \%$, and $105 \%$, respectively. Calibration of the counting systems was done against the mixed standard volume source containing 10 radionuclides.

The detection limits for ${ }^{134} \mathrm{Cs},{ }^{137} \mathrm{Cs}$, and ${ }^{131} \mathrm{I}$ (calculated as three times the fluctuation inherent in the background) were approximately 1,1 , and $0.8 \mathrm{~Bq} \mathrm{~kg}$-dry $^{-1}$, respectively, over a counting period of tens of thousands of seconds. We also determined ${ }^{95} \mathrm{Nb},{ }^{110 \mathrm{~m}} \mathrm{Ag},{ }^{125} \mathrm{Sb},{ }^{129 \mathrm{~m}} \mathrm{Te}$ and ${ }^{129} \mathrm{Te}$, and the detection limits for these radionuclides were almost the same as or lower than those of ${ }^{134} \mathrm{Cs}$ and ${ }^{137} \mathrm{Cs}$, depending on the branching ratio and the gamma-ray energy.

\subsection{Determination of ${ }^{90} \mathrm{Sr}$ and ${ }^{89} \mathrm{Sr}$}

Owing to the time-consuming chemical procedure required for measurement, ${ }^{90} \mathrm{Sr}$ concentrations in the sediments were 


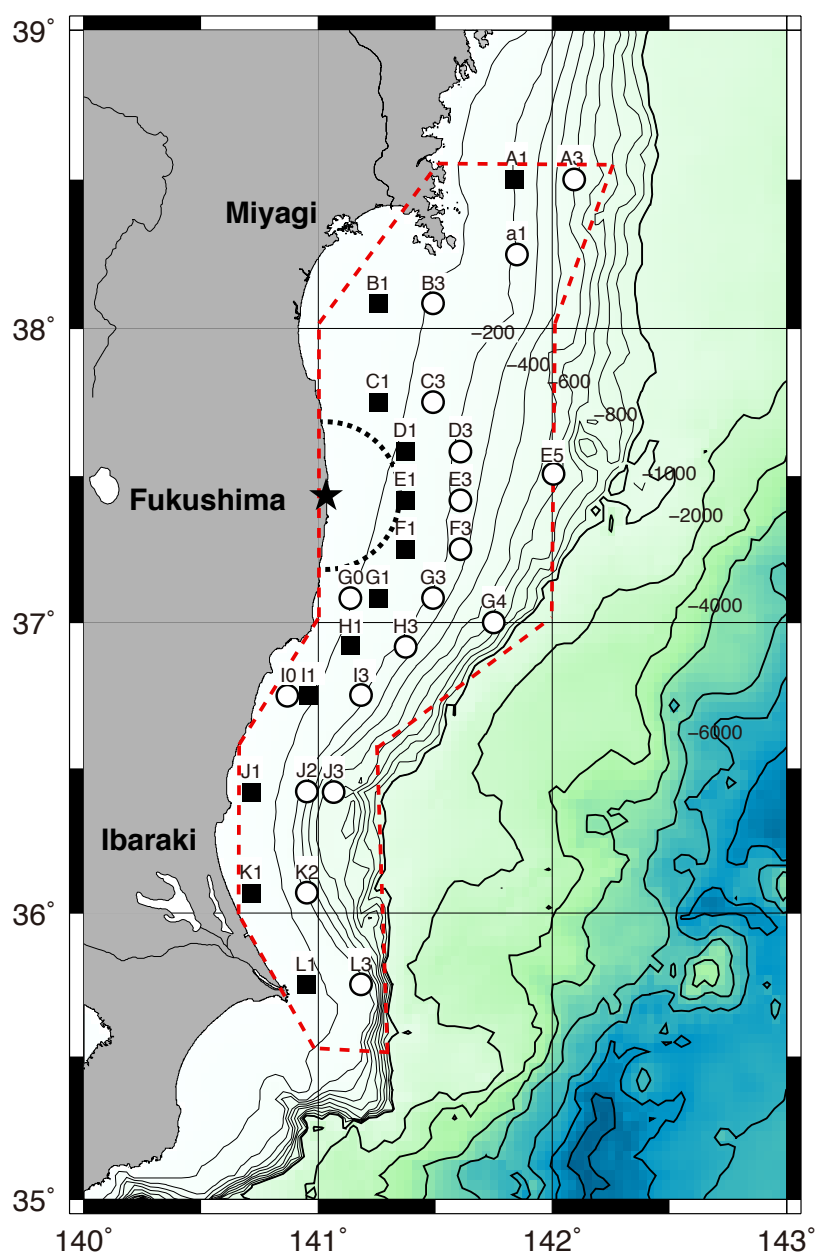

Fig. 2. Locations of sampling stations. Solid squares indicate stations where sediment samples were collected on 10 dates from May 2011 to February 2012, and open circles indicate stations where samples were collected on 4 dates from September 2011 to February 2012. The star indicates the location of the Fukushima Dai-ichi Nuclear Power Plant, and the dashed black semicircle encloses the area within a $30 \mathrm{~km}$ radius of the plant. ${ }^{137} \mathrm{Cs}$ inventories in the sediments were estimated for the area enclosed by the red dashed line (see Sect. 3.1).

measured only in samples containing relatively high concentrations of ${ }^{137} \mathrm{Cs}$.

Strontium was extracted from $300 \mathrm{~g}$ aliquots of dried bottom sediments with $7 \mathrm{M}$ nitric acid after the addition of a known amount of a stable $\mathrm{Sr}^{2+}$ carrier. Strontium was precipitated from the supernatant as strontium oxalate, which was collected by filtration and incinerated at $600^{\circ} \mathrm{C}$ for $3 \mathrm{~h}$. The incineration residue was dissolved in several milliliters of concentrated nitric acid, and the Sr in the resulting nitric acid solution was purified by successive co-precipitation with ferric hydroxide and barium chromate. The decay product of ${ }^{90} \mathrm{Sr},{ }^{90} \mathrm{Y}$ was removed by co-precipitation with ferric hydroxide, and then the supernatant solution was allowed to stand for approximately 2 weeks. The ${ }^{90} \mathrm{Sr}$ concentrations were determined by measuring the beta-rays emitted from ${ }^{90} \mathrm{Y}$ in radioactive equilibrium with ${ }^{90} \mathrm{Sr}$ by means of a gas-flow-type low-background anticoincidence beta counter (LBC-471Q, Aloka Co., Japan). The detection limits, which were calculated as three times the background fluctuation, depended on counting time and sample volume and were approximately $0.8 \mathrm{~Bq} \mathrm{~kg}$-dry ${ }^{-1}$ from May to July 2011 and 0.3 Bq kg-dry $^{-1}$ from September 2011 to February 2012.

The analytical procedure was modified as follows for the samples that were used to measure both ${ }^{89} \mathrm{Sr}$ and ${ }^{90} \mathrm{Sr}$. After the dried samples were dissolved in concentrated nitric acid with an added $\mathrm{Sr}^{++}$carrier, $\mathrm{Sr}$ was purified with an anionexchange resin and then precipitated as strontium carbonate. Beta-rays emitted from the strontium carbonate by the decay of ${ }^{89} \mathrm{Sr},{ }^{90} \mathrm{Sr}$, and ${ }^{90} \mathrm{Y}$ were measured. The ${ }^{90} \mathrm{Y}$ was milked from the strontium carbonate, and its beta-ray emissions were measured to evaluate ${ }^{90} \mathrm{Sr}$ activity (MEXT, 2002). The detection limit for ${ }^{89} \mathrm{Sr}$ was estimated to be $0.8 \mathrm{~Bq} \mathrm{~kg}$ dry $^{-1}$.

\section{Results and discussion}

Most of the data used in this study are available on the MEXT website (http://radioactivity.mext.go.jp/en/list/2/list-1.html). Data obtained during the course of the monitoring project that are relevant to the current study are also provided in the Supplement Tables S1-S3.

\subsection{Distribution of ${ }^{137} \mathrm{Cs}$ in the sediments}

The ${ }^{137} \mathrm{Cs}$ concentrations in the surface sediments varied tremendously with respect to both time and space (Fig. 3), ranging from 1.7 to $580 \mathrm{~Bq} \mathrm{~kg}$-dry ${ }^{-1}$ over the course of the entire sampling period (May 2011 to February 2012). The concentrations were at most two orders of magnitude greater than the concentrations measured in 2010 at eight sampling stations off Fukushima Prefecture (MEXT, 2011; Fig. 1). Although the stations in the northernmost and southernmost parts of the monitoring area (e.g., A1, A3, L1, and L3) were least influenced by the accident, close proximity of a sampling station to the FDNPP did not necessarily result in a high ${ }^{137}$ Cs concentration. From May to July 2011, when sampling was restricted to areas relatively close to the coast, the concentrations were higher at the northern stations (e.g., B1, C1, and D1) than the rest of the stations, and the concentration was also consistently high at Stn. J1. From September 2011 to February 2012, the concentration at Stn. B3 was substantially higher than at the other stations. It should be noted that monitoring at Stn. B3 was not conducted prior to September 2011.

Ambe et al. (2012) took 40 sediment samples in the waters off Fukushima Prefecture outside of the $20 \mathrm{~km}$ radius of the plant in February 2012. They found that ${ }^{137} \mathrm{Cs}$ concentration 


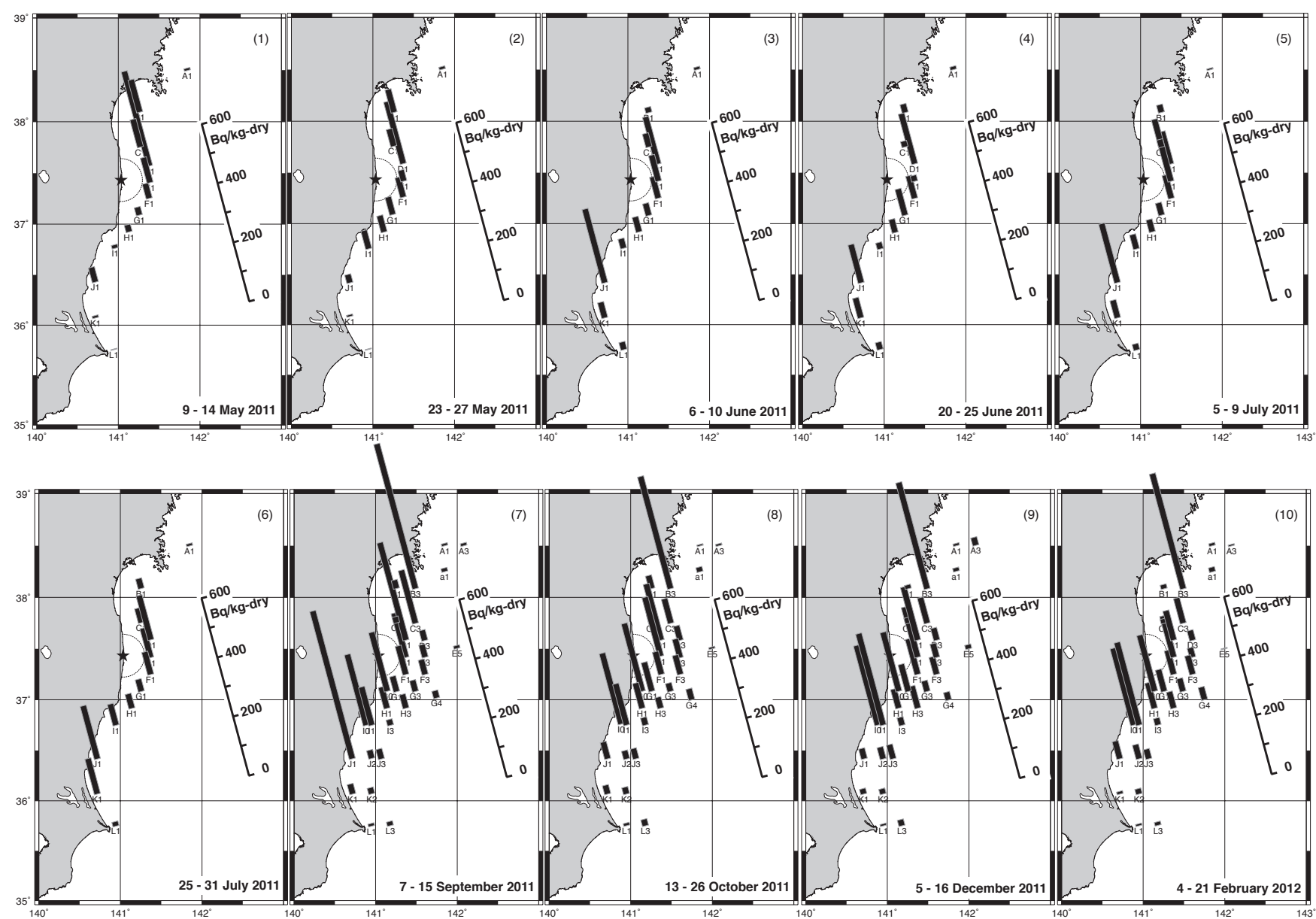

Fig. 3. Spatiotemporal distribution of ${ }^{137}$ Cs concentrations in sediment samples collected on the dates indicated in the panels. Six sediment samples were collected at Stn. D1 on 13 September 2011, and the average value for the six samples is plotted in the figure (see Sect. 3.1 and Fig. 5).

in the surface sediments $(0-1 \mathrm{~cm}$ layer) ranged from 17 to $1082 \mathrm{~Bq} \mathrm{~kg}^{-d_{r y}}{ }^{-1}$. Although their sampling locations were not necessary the same as those in this report, several data from the nearby stations seemed to be higher than the present values. The difference in the concentrations could be ascribed to the difference in depth intervals of sampling for the surface sediments, that is, $1 \mathrm{~cm}$ and $3 \mathrm{~cm}$. The ${ }^{137} \mathrm{Cs}$ concentration in the surface sediments was assumed to decline with depth. Thus, the thicker sampling depths might have resulted in somewhat lower concentrations, especially in the early stage of the monitoring when bioturbation in the surface sediments was yet to have an effect to lessen the steep concentration gradient.

The temporal variations of the ${ }^{137} \mathrm{Cs}$ concentrations at all the stations are shown in Fig. 4. Early in the sampling period (May-June 2011), the concentrations varied considerably with sampling date, especially for the stations in the southern portion of the monitoring area (e.g., I1, J1, K1, and L1). After September 2011, however, there was generally much less temporal variation of the concentrations. We con- sidered several possible explanations for the observed variability of the ${ }^{137} \mathrm{Cs}$ concentrations in the sediments throughout the monitoring period.

One explanation is local heterogeneity in the physical and chemical characteristics of the sediments; these characteristics affect incorporation of Cs from seawater into the sediments. For evaluation of the effects of sediment heterogeneity, six bottom sediment samples were collected in succession at Stn. D1 on 13 September 2011, and their ${ }^{137}$ Cs concentrations and ${ }^{134} \mathrm{Cs} /{ }^{137} \mathrm{Cs}$ activity ratios were determined (Fig. 5). Although the activity ratios were relatively constant, meaning that the isotopes had a common origin, the ${ }^{137} \mathrm{Cs}$ concentrations ranged from 170 to $580 \mathrm{~Bq} \mathrm{kg-dry}{ }^{-1}$, with an average and standard deviation of $330 \pm 160 \mathrm{~Bq} \mathrm{~kg}^{-d_{r y}}{ }^{-1}$. Thus, some of the variation of the concentrations shown in Figs. 3 and 4 was likely to reflect local heterogeneity of the ${ }^{137} \mathrm{Cs}$ concentrations in the sediments.

Another possible explanation was mobility of the topmost layer of sediments. Because the surface sediment layer most enriched with ${ }^{137} \mathrm{Cs}$ was assumed to be thin due to its short 


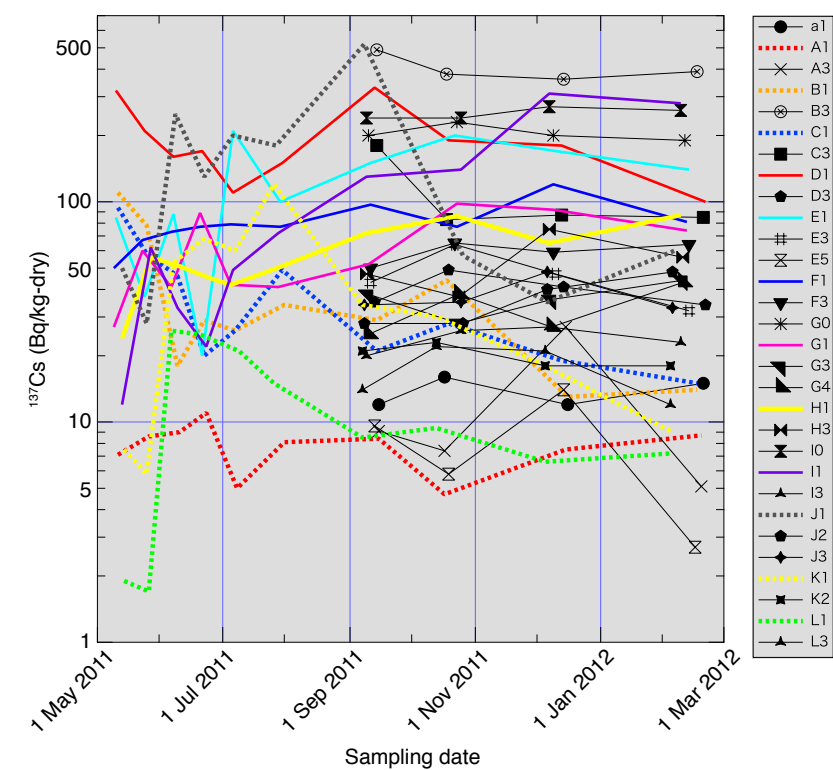

Fig. 4. Temporal variations of ${ }^{137} \mathrm{Cs}$ concentrations in the sediments. Six sediment samples were collected at Stn. D1 on 13 September 2011, and the average of the six concentrations is plotted in the figure (see Sect. 3.1 and Fig. 5).

accumulation period from March 2011 to February 2012, it could be remobilized by bottom-water turbulence, especially in coastal waters. Otosaka and Kobayashi (2012) suggested that radiocesium is transported laterally by resuspended sediments. If this was so for the present case, then the physics of the bottom water could be expected to play an important role in the variability of ${ }^{137} \mathrm{Cs}$ concentration.

A sampling artifact resulting from loss of surface sediments during sample retrieval might be possible. But we thought it was unlikely because the multiple corer used to collect the samples usually preserves the surface sediments intact. In addition, although we used a global positioning system to locate the predefined sampling stations, positional deviations due to current and wind were inevitable, as indicated by the fact that there was a great deal of scatter in data from a given station in different years (Fig. 1).

Finally, the pathways for nuclide migration to the sediments might have been variable, and this possibility is discussed in Sect. 3.4.

\subsection{Distribution of ${ }^{134} \mathrm{Cs}$ in the sediments}

The distribution of FDNPP-derived ${ }^{134} \mathrm{Cs}$, which has a shorter half-life $(2.06 \mathrm{yr})$ than ${ }^{137} \mathrm{Cs}$, is expected to be identical to that of ${ }^{137} \mathrm{Cs}$, except for differences due to decay. We plotted the temporal variation of the ${ }^{134} \mathrm{Cs} /{ }^{137} \mathrm{Cs}$ ratio in the sediments (Fig. 6), and a weighted least-squares fit of the data indicated that the ratio decreased with time at a firstorder rate of $-8.68 \times 10^{-4} \mathrm{day}^{-1}$, which was equivalent to a half-life of $2.18 \mathrm{yr}$ and thus agreed well with the known

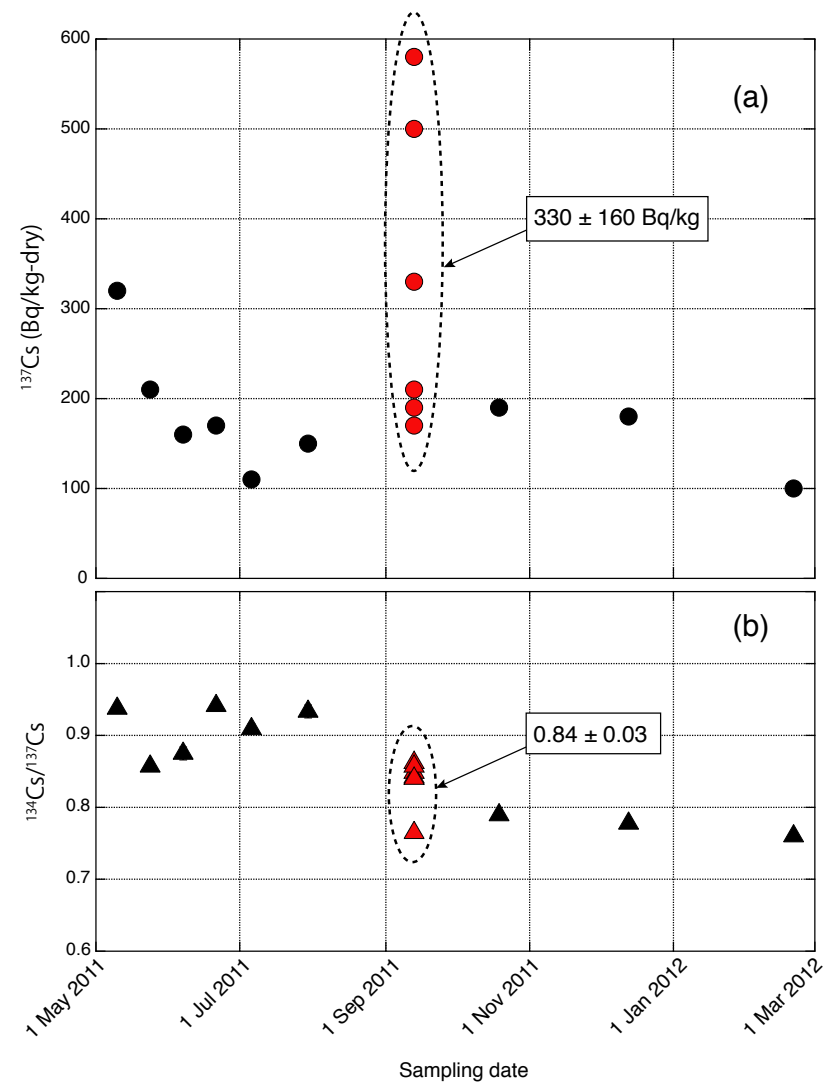

Fig. 5. (a) Temporal variation of ${ }^{137} \mathrm{Cs}$ concentrations in sediment samples collected at Stn. D1 (black circles) and reproducibility as indicated by data for six samples collected on 13 September 2011 (red circles). For each data point, the error is less than or equal to the size of the circle. (b) Temporal variation of ${ }^{134} \mathrm{Cs} /{ }^{137} \mathrm{Cs}$ in sediment samples collected at Stn. D1 (black triangles) and reproducibility as indicated by data for six samples collected on 13 September 2011 (red triangles). For each data point, the error is less than or equal to the size of the triangle.

half-life of ${ }^{134} \mathrm{Cs}$. The good correlation $\left(R^{2}=0.73\right)$ of the fit indicated that the ${ }^{134} \mathrm{Cs}$ distribution mimicked that of ${ }^{137} \mathrm{Cs}$. The fit equation gave an intercept of 0.989 on 11 March 2011, which agreed well with the ratio for seawater (0.93) reported by Oikawa et al. (2013) and other investigators (e.g., Buesseler et al., 2012; Aoyama et al., 2012).

\subsection{Inventory of ${ }^{137} \mathrm{Cs}$ in the sediments}

Inventories of ${ }^{137} \mathrm{Cs}\left(I_{\mathrm{Cs}}, \mathrm{Bq} \mathrm{m}^{-2}\right)$ in the upper $3 \mathrm{~cm}$ of the sediments were calculated from sediment bulk densities $\left(D_{\mathrm{s}}\right)$, water contents $\left(W_{\mathrm{s}}\right)$, and ${ }^{137} \mathrm{Cs}$ concentrations $\left(C_{\mathrm{Cs}}\right.$, Bq kg-dry $\left.^{-1}\right)$ :

$I_{\mathrm{Cs}}=D_{\mathrm{s}}\left(1-W_{\mathrm{s}}\right) C_{\mathrm{Cs}} \times 3 \times 1000$,

and the results are plotted in Fig. 7. The spatial distribution patterns of the inventories were generally similar to the concentration patterns, with some notable exceptions. For 


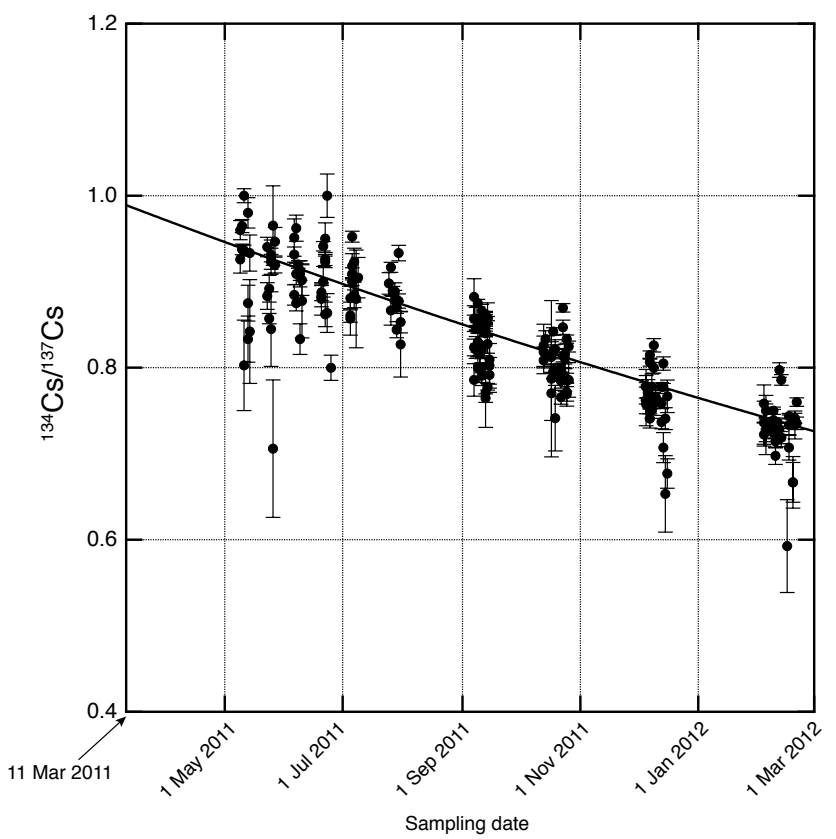

Fig. 6. Temporal variation of ${ }^{134} \mathrm{Cs} /{ }^{137} \mathrm{Cs}$ ratio in the sediments. The line represents the result of a weighted least-squares fit and corresponds to the following equation: ${ }^{134} \mathrm{Cs} /{ }^{137} \mathrm{Cs}=c_{1} \exp \left(-c_{2} t\right)$, where $c_{1}=0.989$ and $c_{2}=0.000868$.

example, although the concentrations at Stn. B3 were consistently high (Fig. 3), the inventory at that station was not particularly high compared to the inventories at the other stations due to its low bulk density, i.e., high water content. While the bulk density and water content of Stn. B3 were around 1.2 and 0.7 , those of the nearby station B1 were $1.8-2.0$ and $0.15-0.19$, respectively (see Table S1). The relationships among the ${ }^{137} \mathrm{Cs}$ concentration, inventory and bulk density values are shown in Fig. $8 .{ }^{137} \mathrm{Cs}$ concentration and inventory were linearly correlated, but the slope varied with bulk density.

On the basis of the estimated area $\left(22177 \mathrm{~km}^{2}\right.$, enclosed by the red dashed line in Fig. 2) and the average inventory $\left(0.161 \mathrm{~Bq} \mathrm{~cm}^{-2}\right)$ for the last sampling date (February 2012), we calculated the total amount of ${ }^{137} \mathrm{Cs}$ in the monitoring area to be $3.78 \times 10^{13} \mathrm{~Bq}$. This value was clearly an underestimate of the actual value because the inventory data were restricted to the upper $3 \mathrm{~cm}$ of sediments, and the monitoring area did not cover the entire contaminated area. Otosaka and Kobayashi (2012) detected Fukushima-derived ${ }^{137} \mathrm{Cs}$ below the upper $3 \mathrm{~cm}$ of sediments, and ${ }^{137} \mathrm{Cs}$ penetrated deeper into sandy sediment than into clay sediment. Thus, the calculated inventory must be regarded as an approximate estimate.

Various estimates of the total amount of ${ }^{137} \mathrm{Cs}$ directly released to the ocean following the accident at FDNPP have been reported, ranging from $2 \times 10^{15}$ to $1.5 \times 10^{16} \mathrm{~Bq}$, depending on the model used (e.g., IRSN, 2011; Masumoto et al., 2012; Tsumune et al., 2012). In addition, Bailly du Bois et al. (2012) calculated the amount to be $2.7 \times 10^{16} \mathrm{~Bq}$. The contribution of airborne ${ }^{137} \mathrm{Cs}$ to the ocean inventory may not be significant. The amount of ${ }^{137} \mathrm{Cs}$ discharged into the atmosphere was estimated to be $1.3 \times 10^{16} \mathrm{~Bq}$ (Chino et al., 2011), and the amount deposited from the atmosphere to the ocean over an $80 \mathrm{~km}$ radius from the FDNPP was estimated to be $7.6 \times 10^{13} \mathrm{~Bq}$ (Bailly du Bois et al., 2012). If we used our estimated value of $3.78 \times 10^{13} \mathrm{~Bq}$ as the total inventory of ${ }^{137} \mathrm{Cs}$ in the monitoring area as of February 2012, 0.1-2\% of the total ${ }^{137} \mathrm{Cs}$ flux from the plant to the ocean was deposited onto the bottom sediments, with the actual percentage depending on which estimate of the total ${ }^{137} \mathrm{Cs}$ flux was used. More accurate quantification of the mass balance of ${ }^{137} \mathrm{Cs}$ in the coastal ocean will require expansion of the monitoring area, especially in the proximity of the FDNPP, detailed study of the vertical profile of ${ }^{137} \mathrm{Cs}$ in the sediments, and a more accurate evaluation of its flux to the ocean.

Because it is important to determine whether the total inventory of ${ }^{137} \mathrm{Cs}$ in sediments has been changing since the accident at Fukushima, we roughly estimated the temporal variation of ${ }^{137} \mathrm{Cs}$ inventories. Average inventories were determined for sediment samples collected over the entire 10 month sampling period (Table 1) at stations with designations including the number 1 (A1, B1, etc.) and for sediment samples collected over the 6-month period starting in September 2011 at all the stations. The average inventories for the former set of stations were highly variable and did not show any clear increasing trend; on the other hand, the inventories appeared to decrease from September 2011 onward (Table 1), as did the inventories for all the sediment samples collected in the monitoring area (Fig. 2). Specifically, the total inventory of ${ }^{137} \mathrm{Cs}$ in the monitoring area decreased from $5.16 \times 10^{13} \mathrm{~Bq}$ in September 2011 to $3.78 \times 10^{13} \mathrm{~Bq}$ in February 2012 (Table 1). However, because of the abovementioned variability of the ${ }^{137} \mathrm{Cs}$ concentration in the samples collected repeatedly from the same station (Fig. 5), it would be premature to conclude that the inventory showed a decreasing trend. If the total inventory of ${ }^{137} \mathrm{Cs}$ in the upper $3 \mathrm{~cm}$ of sediments did decrease, the decrease might have been due to bioturbation that carried Cs deeper into the sediments and/or due to lateral transport of resuspended sediments to the open ocean, as suggested by Otosaka and Kobayashi (2012).

\subsection{Removal of ${ }^{137} \mathrm{Cs}$ from seawater to the sediments}

The concentration of ${ }^{137} \mathrm{Cs}$ in the sediment samples depended on the sediment types. As expected from Fig. 8, the ${ }^{137} \mathrm{Cs}$ concentrations were expected to be inversely correlated with sediment bulk density. The concentrations are plotted against sediment bulk density in Fig. 9. The correlation coefficient was calculated to be -0.43 . Results from monitoring in the same area prior to the FDNPP accident suggest that sediment with relatively low bulk density has a finer grain size (i.e., clay) and abundant organic matter 


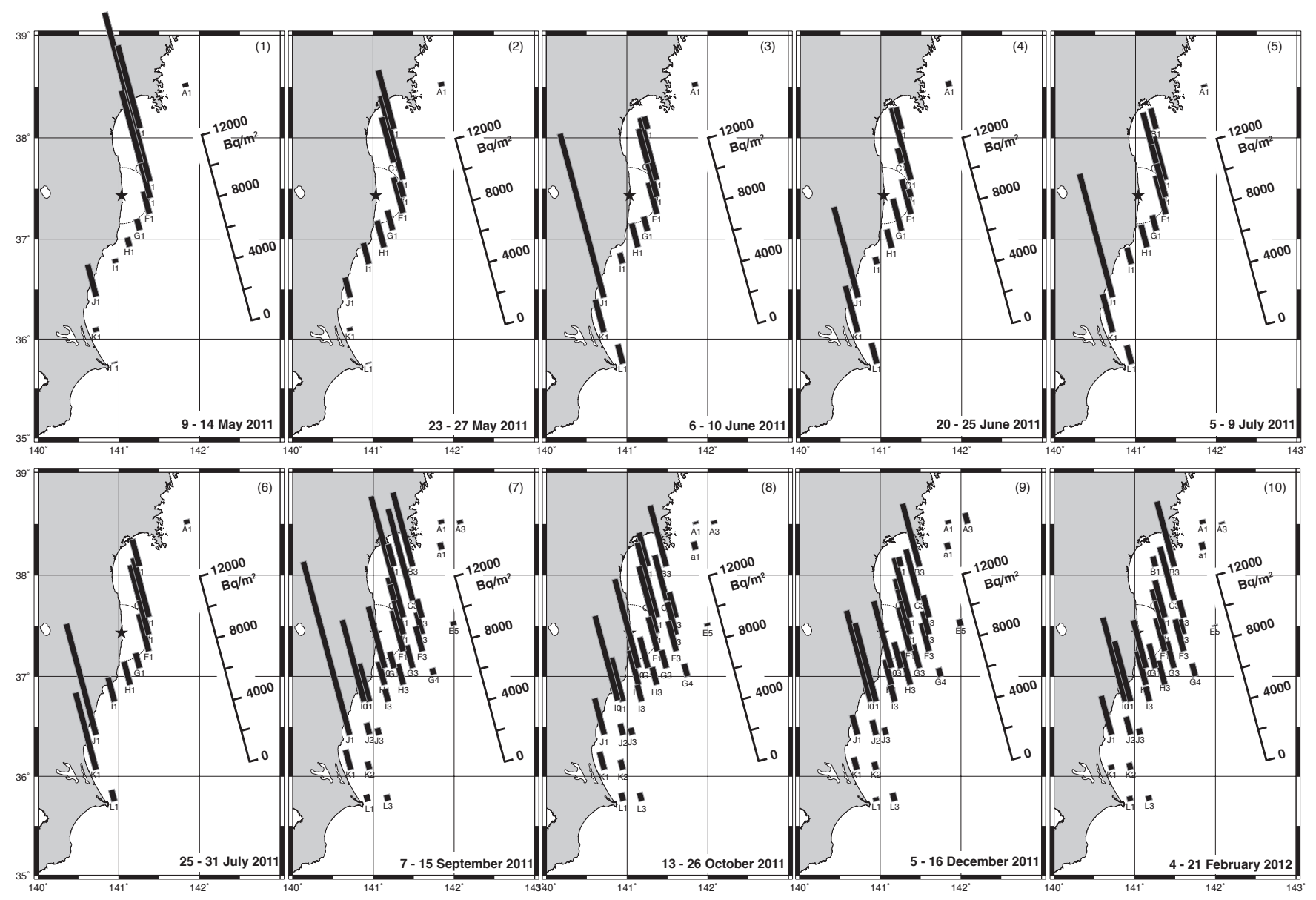

Fig. 7. Spatiotemporal variation of ${ }^{137}$ Cs inventory in sediment samples collected on the dates indicated in the panels.

Table 1. Inventories of ${ }^{137} \mathrm{Cs}$ in the upper $3 \mathrm{~cm}$ of the surface sediments.

\begin{tabular}{lccc}
\hline $\begin{array}{l}\text { Sampling } \\
\text { date }\end{array}$ & $\begin{array}{c}\text { Average } \\
\text { inventory }(1)^{\mathrm{a}} \\
\left(\times 10^{3} \mathrm{~Bq} \mathrm{~m}^{-2}\right)\end{array}$ & $\begin{array}{c}\text { Average } \\
\text { inventory }(2)^{\mathrm{b}} \\
\left(\times 10^{3} \mathrm{~Bq} \mathrm{~m}^{-2}\right)\end{array}$ & Inventory $^{c}$ \\
$\left(\times 10^{13} \mathrm{~Bq}\right)$ \\
\hline 9-14 May 2011 & 2.44 & - & - \\
23-27 May 2011 & 1.80 & - & - \\
6-10 June 2011 & 2.40 & - & - \\
20-25 June 2011 & 2.01 & - & - \\
5-09 July 2011 & 2.38 & - & - \\
25-31 July 2011 & 2.50 & - & - \\
7-15 September 2011 & 2.88 & 2.20 & 5.16 \\
13-26 October 2011 & 2.17 & 1.91 & 4.49 \\
5-16 December 2011 & 1.88 & 1.81 & 4.24 \\
4-21 February 2012 & 1.65 & 1.61 & 3.78 \\
\hline
\end{tabular}

a Average inventory for the sediments collected at Stns. A1, B1, C1, D1, E1, F1, G1, H1, I, J1, K1,

and L1.

$\mathrm{b}$ Average inventory for all the stations monitored since September 2011.

c Total inventory in the area enclosed by the red dashed line in Fig. 1.

content (Marine Ecology Research Institute, unpublished data). These results imply that $\mathrm{Cs}$ tended to concentrate preferentially on sediments that were fine grained, rich in or- ganic matter, or both. The strong affinity of Cs for clay minerals has been well documented (e.g., Børrentzen and Salbu, 2002; Tsukada et al., 2008; Qin et al., 2012). Otosaka 


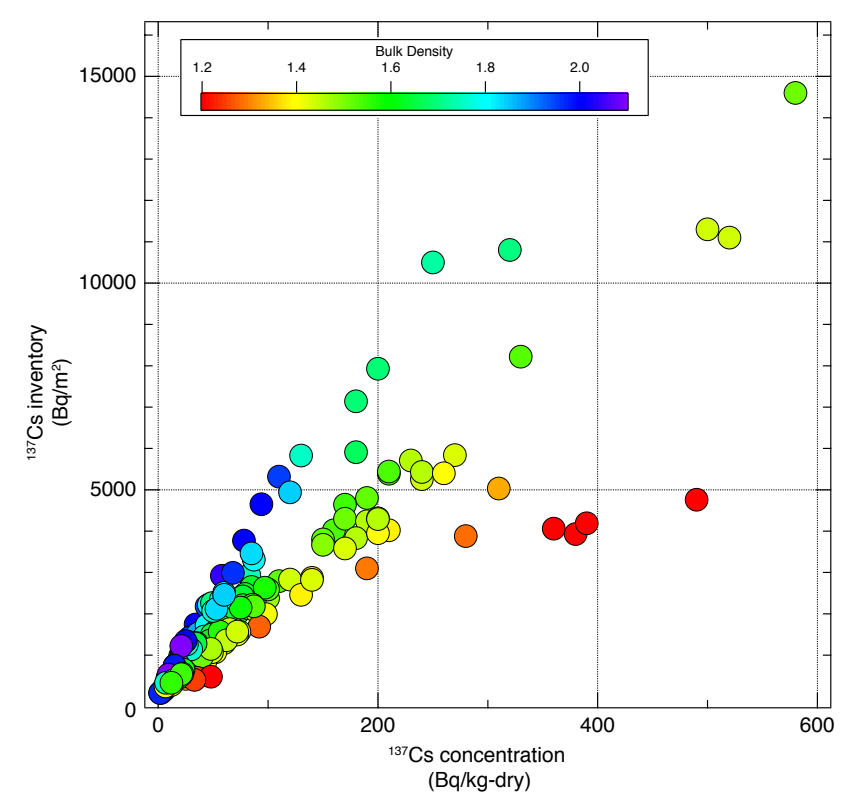

Fig. 8. Variation of ${ }^{137} \mathrm{Cs}$ inventory in sediments with ${ }^{137} \mathrm{Cs}$ concentration in sediments at various sediment bulk densities.

and Kobayashi (2012) measured Fukushima-derived ${ }^{137} \mathrm{Cs}$ concentrations in coastal sediments off Ibaraki Prefecture and showed that fine-grained sediments have higher ${ }^{137} \mathrm{Cs}$ concentrations than coarse-grained sediments. However, the scatter of the data in Fig. 9 indicated that sediment mineralogy alone could not completely account for the spatial distribution of ${ }^{137} \mathrm{Cs}$ in the sediments.

The concentration of ${ }^{137} \mathrm{Cs}$ in the surface water above the sediments could be expected to affect the concentrations in the sediments. The rate of ${ }^{137} \mathrm{Cs}$ release to the ocean reached its maximum value $\left(\sim 0.1 \mathrm{PBq}\right.$ day $\left.^{-1}\right)$ in early April and then began to decrease exponentially (Kawamura et al., 2011; Tsumune et al., 2012). On 14 April, the ${ }^{137} \mathrm{Cs}$ concentration in the surface water reached its maximum of $\sim 190 \mathrm{BqL}^{-1}$ at Stn. 4 ( $\sim 4 \mathrm{~km}$ away from Stn. E1), where no sediment sample was collected (Oikawa, et al., 2013). After that date, the concentration in the surface water decreased exponentially. In July, the maximum concentration was $\sim 1 \mathrm{BqL}^{-1}$. From April to July, the ${ }^{137} \mathrm{Cs}$ inventory in a $100 \times 50 \mathrm{~km}$ box off Fukushima declined by almost four orders of magnitude (Bailly du Bois et al., 2012). Thus, most of the ${ }^{137} \mathrm{Cs}$ released from the FDNPP can be accounted for by integration of ${ }^{137} \mathrm{Cs}$ concentrations in the surface water from April to July.

We investigated the relationship between ${ }^{137} \mathrm{Cs}$ concentrations integrated from May to July 2011 in the surface seawater $(<5 \mathrm{~m}$ depth) and concentrations in sediments averaged from September 2011 to February 2012 (Fig. 10). The average concentration of ${ }^{137} \mathrm{Cs}$ in surface sediments was positively correlated with the integrated seawater concentration at each station, but in sediments with relatively high bulk density (that is, sandy sediment), the ${ }^{137} \mathrm{Cs}$ concentrations

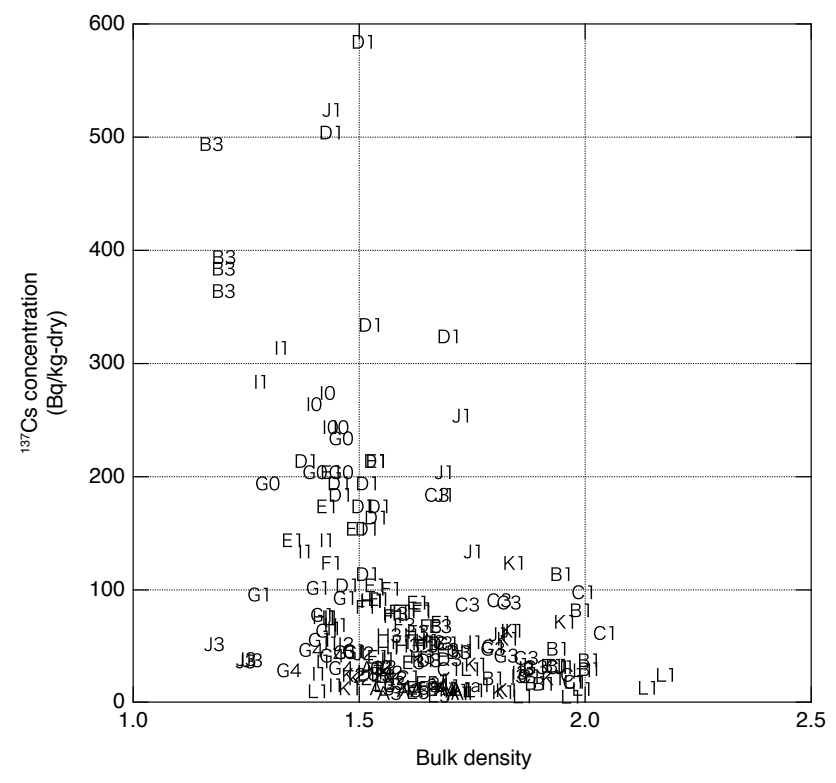

Fig. 9. Variation of ${ }^{137} \mathrm{Cs}$ concentrations with sediment bulk density at the sampling stations shown in Fig. 3.

were lower (Stns. L1, K1, I3, B1, and C1). The data in the figure suggested that the higher ${ }^{137} \mathrm{Cs}$ concentrations in sediments were derived from higher concentrations in the overlying surface seawater, and ${ }^{137} \mathrm{Cs}$ was associated with sediments rich in clay, organic matter, or both. In other words, fine settling particles enriched in ${ }^{137} \mathrm{Cs}$ accumulated in areas where they could reach the bottom without being disturbed by strong turbulence. Oikawa et al. (2013) qualitatively described a scenario for the migration of surface ${ }^{137} \mathrm{Cs}$ after the accident as follows: in early May 2011, all the ${ }^{137}$ Cs-polluted water migrated north, and at the end of May 2011 some of it went south to around Stns. I1, J1, and K1 while the remainder stayed around Stns. B1 and B3. Two water masses with high ${ }^{137} \mathrm{Cs}$ concentrations in the south and north persisted at least until July 2011. These investigators' interpretation of the surface distribution is in accordance with the sediment distribution we found: that is, relatively high concentrations in the north (e.g., at Stn. B3) and in the south (e.g., at Stn. J1). Admittedly the scenario presented by Oikawa et al. (2013) is crude because of the lack of seawater concentration data in April 2011. Simulation results reported by Tsumune et al. (2012), however, suggest that the influence of highly polluted water was restricted to a relatively small portion of the monitoring area, so that the overall trend shown in Fig. 10 may not be affected by the lack of the data in April 2011.

The mechanism for the accumulation of ${ }^{137} \mathrm{Cs}$ in the sediments presented above is based on the assumption that $\mathrm{Cs}$ removal from seawater occurs rapidly enough that the distribution of Cs in the sediments reflects that of the overlying seawater. Cesium is soluble in seawater, but once it is incorporated into particles, it is rapidly removed from seawater 


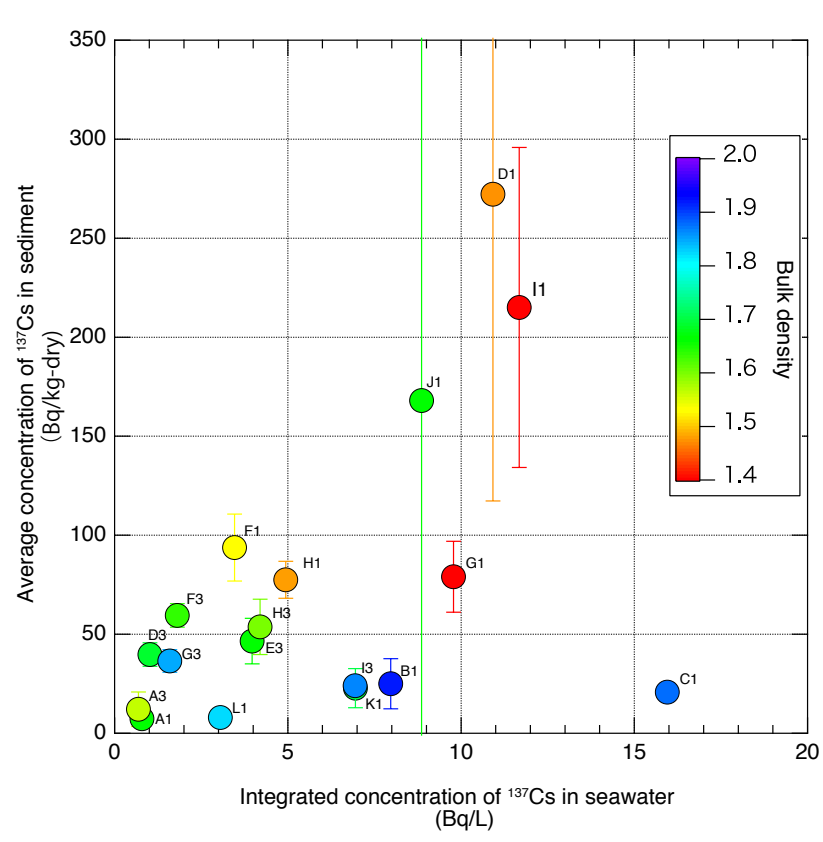

Fig. 10. Average ${ }^{137} \mathrm{Cs}$ concentrations in sediments, integrated ${ }^{137} \mathrm{Cs}$ concentrations in seawater, and average sediment bulk densities at the sampling stations where seawater concentrations were available during six cruises from May to July 2011. Integrated concentrations of ${ }^{137} \mathrm{Cs}$ in seawater were calculated to sum all the data obtained in the six cruises for each station. Average ${ }^{137} \mathrm{Cs}$ concentrations in sediments were calculated for samples obtained from September 2011 to February 2012. Error bars indicate the standard deviations of the sediment concentrations.

to the bottom sediments. Fowler et al. (1987) observed that Chernobyl-derived radionuclides, including ${ }^{137} \mathrm{Cs}$, were transported from the surface of the Black Sea to a depth of $200 \mathrm{~m}$ in a few days. These investigators emphasized the importance of large, dense fecal pellets of zooplankton as nuclide carriers. Kusakabe et al. (1988) estimated the settling velocities of Chernobyl-derived particulate ${ }^{137} \mathrm{Cs}$ to be 60 $190 \mathrm{~m} \mathrm{day}^{-1}$ in the northern North Pacific. Fast removal of particulate Cs may result in a relatively good relationship between the integrated concentration of ${ }^{137} \mathrm{Cs}$ in surface seawater and the average ${ }^{137} \mathrm{Cs}$ concentration in sediments. Possible elevation of particulate matter content in seawater due to the tsunami of March 2011 may have enhanced scavenging of $\mathrm{Cs}$ and downward transportation in the months immediately after. However, so far there has been little information about this matter yet. The possibility of fast removal of nuclides from seawater is also described in Sects. 3.5 and 3.7.

\subsection{Distribution of ${ }^{131} \mathrm{I}$ in the sediments}

The concentration of ${ }^{131} \mathrm{I}$ in the sediments reached a maximum of $6.1 \mathrm{~Bq} \mathrm{~kg}$-dry ${ }^{-1}$ at Stn. G1 on 9 May 2011 and then decreased quickly owing to its short half-life of 8 days (Fig. 11). ${ }^{131}$ I was last detected on 8 June 2011 (1.3 Bq kg- dry $^{-1}$ at Stn. J1), and since then no ${ }^{131} \mathrm{I}$ has been detected in the sediments.

During the monitoring program off Fukushima, seawater and airborne dust were analyzed for radioactivity (MEXT, 2012), and we compared the ${ }^{131} \mathrm{I} /{ }^{137} \mathrm{Cs}$ activity ratios in sediments with the ratios in airborne dust and seawater (Fig. 11). The concentration of ${ }^{131} \mathrm{I}$ in dust, which was measured from 23 March 2011 in the waters in the vicinity of the FDNPP, reached a maximum at the end of March, and decreased to below the detection limit by 7 April 2011 (MEXT, 2012). The ${ }^{131} \mathrm{I} /{ }^{137} \mathrm{Cs}$ activity ratios in dust and seawater varied by an order of magnitude in the middle of April 2011, and the ratios in seawater seemed to converged to a value that has followed its decay trend since then. On the basis of an analysis of ${ }^{131} \mathrm{I} /{ }^{137} \mathrm{Cs}$ activity ratios in seawater $30 \mathrm{~km}$ off the FDNPP, Tsumune et al. (2012) inferred that although both nuclides in the area were derived mainly from the atmosphere until 9 April 2011, they were dominated by direct discharge after that date. The ${ }^{131} \mathrm{I} /{ }^{137} \mathrm{Cs}$ ratio at the discharge site on 26 March 2011 was estimated to be 5.7. The theoretical decay curve based on this estimate (see the line in Fig. 11) indicated that although the ratios in the sediments fell along the line, the scatter about the regression line was greater for the sediments versus seawater in April 2011. Several points of deviation from the line may have been due to atmospheric input, the ratios of which vary with time (Chino et al., 2011).

The chemistries of I and Cs in seawater are different, especially in terms of their removal from seawater. For example, the distribution coefficients, $K_{\mathrm{d}} \mathrm{s}$, of I and Cs in the marginal sea are $7 \times 10^{1}$ and $4 \times 10^{3}$, respectively (IAEA, 2004); this indicates that $\mathrm{Cs}$ is more easily adsorbed onto or incorporated into particles than $\mathrm{I}$, and as a result the ${ }^{131} \mathrm{I} /{ }^{137} \mathrm{Cs}$ ratios in sediments should be smaller than those in seawater. However, the data in Fig. 11 did not show such a consistent trend and they might reflect the variability of the ${ }^{131} \mathrm{I} /{ }^{137} \mathrm{Cs}$ ratios in seawater and dust, implying that both nuclides were removed from seawater to the sediments at the same time in a short period of time.

\subsection{Distribution of ${ }^{90} \mathrm{Sr}$ in the sediments}

Five sediment samples were analyzed for ${ }^{89} \mathrm{Sr}$ (Supplement Table S3), but none of them had a ${ }^{89} \mathrm{Sr}$ concentration above the detection limit. Concentration of ${ }^{90} \mathrm{Sr}$ in surface seawater was measured from August to November 2011, and showed only 2 to 4 -fold increase compared to pre-accident values, unlike ${ }^{137} \mathrm{Cs}$, which showed about 2 orders of magnitudes increase in the same period (Oikawa et al., 2013). ${ }^{90} \mathrm{Sr}$ was not detected in the sediments collected from May to July 2011, probably owing to the relatively high detection limit (see Sect. 2.3). The concentrations in the samples collected starting in September 2011 ranged from 0.1 to $1.9 \mathrm{~Bq} \mathrm{~kg}$-dry $^{-1}$, but most of the data fell in the range from 0.1 to $0.3 \mathrm{~Bq} \mathrm{~kg}$ dry $^{-1}$ (Fig. 12). It should be noted that the data below the detection limit are not plotted in the figure. A much higher 


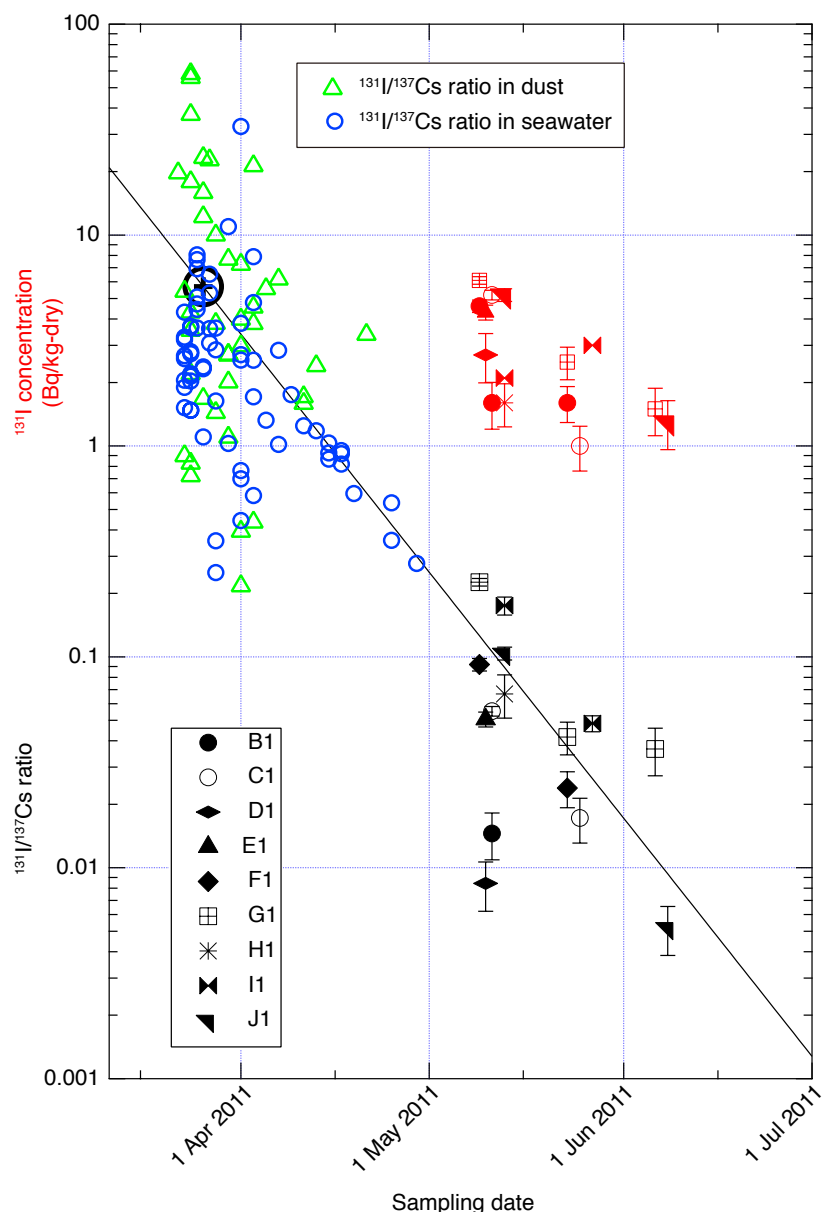

Fig. 11. Temporal variations of ${ }^{131} \mathrm{I}$ concentration and ${ }^{131} \mathrm{I} /{ }^{137} \mathrm{Cs}$ ratios in airborne dust, seawater, and sediments. The line shows the decay curve of the ${ }^{131} \mathrm{I} /{ }^{137} \mathrm{Cs}$ ratio based on an estimated initial ratio of 5.7 on 26 March 2011 (indicated by the circled cross; see Sect. 3.5 and Tsumune et al., 2012). ${ }^{131} \mathrm{I} /{ }^{137} \mathrm{Cs}$ ratios in dust and seawater were derived from data reported by MEXT (2012) and Oikawa et al. (2013, respectively).

concentration (1.9 Bq kg-dry ${ }^{-1}$ ) was measured at Stn. J1. Unfortunately, background ${ }^{90} \mathrm{Sr}$ concentrations in the area before the accident are not available. However, ${ }^{90} \mathrm{Sr}$ has been measured in the sediments collected from the waters off Aomori and Iwate Prefectures, which are north of Miyagi Prefecture; the measured concentrations range from 0 (below the detection limit) to $0.51 \mathrm{~Bq} \mathrm{~kg}^{-\mathrm{dry}^{-1}}$ (MEXT, 2011). Thus, the ${ }^{90} \mathrm{Sr}$ concentrations that we measured seemed to indicate that the sediments were not contaminated by Fukushimaderived Sr. The high ${ }^{90} \mathrm{Sr}$ concentration in the sediments collected from Stn. J1 may not have been due to the accident, because ${ }^{89} \mathrm{Sr}$, which has a half-life of 50.5 days and is believed to be a Fukushima-derived radioisotope, was not detected. The reason for the high ${ }^{90} \mathrm{Sr}$ concentration at Stn. J1 is unknown.

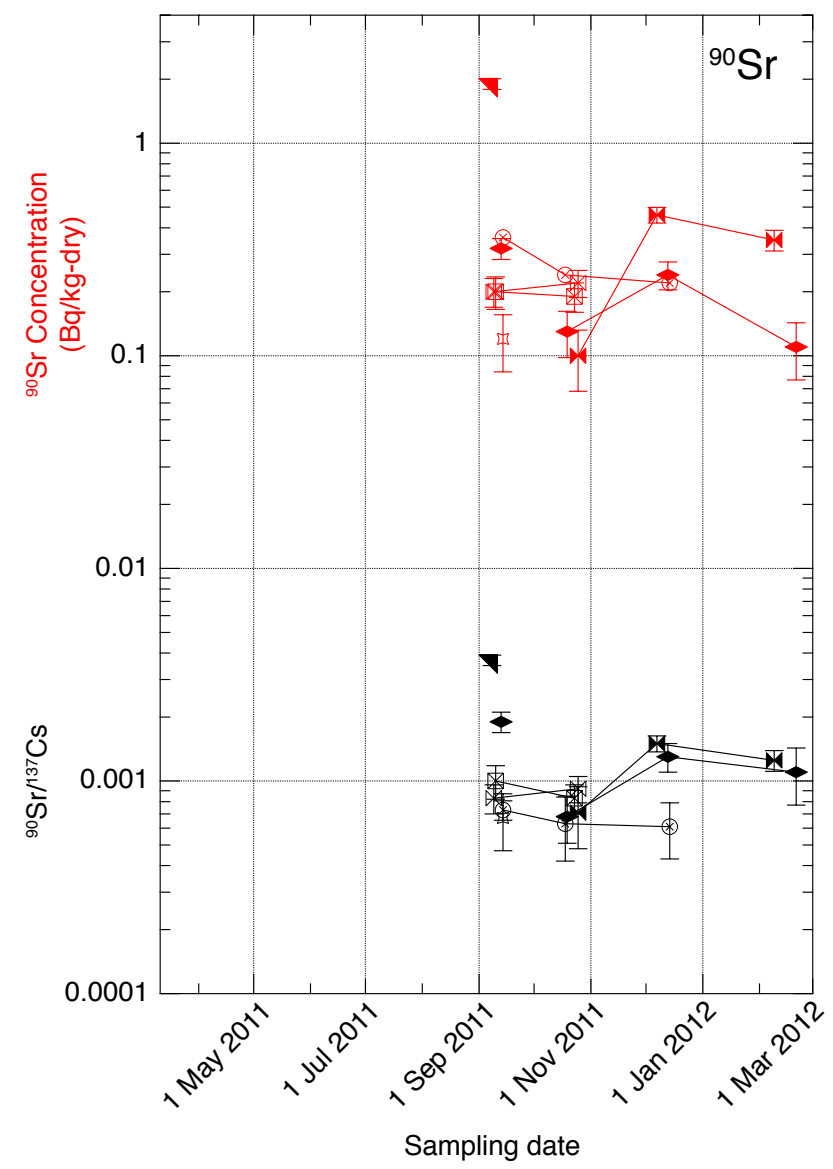

Fig. 12. Temporal variations of ${ }^{90} \mathrm{Sr}$ concentrations (red symbols) and ${ }^{90} \mathrm{Sr} /{ }^{137} \mathrm{Cs}$ ratios (black symbols) in the sediments. Values below the detection limit are not shown. See Fig. 13 for a key to the symbols.

Most of the ${ }^{90} \mathrm{Sr} /{ }^{137} \mathrm{Cs}$ activity ratios were below 0.001 (Fig. 12). In 2010, the average ${ }^{90} \mathrm{Sr} /{ }^{137} \mathrm{Cs}$ ratio in surface sediments off Aomori Prefecture (to the north of Fukushima) was 0.11 and that in seawater was 0.79 (MEXT, 2011). Although these sampling areas off Aomori and Fukushima do not overlap each other, the lack of a significant change in the ${ }^{90} \mathrm{Sr}$ concentration and the lower ${ }^{90} \mathrm{Sr} /{ }^{137} \mathrm{Cs}$ activity ratio after the accident can be explained only by preferential removal of Cs over $\mathrm{Sr}$. The fact that the $K_{\mathrm{d}}$ value of $\mathrm{Sr}$ for the marginal sea was estimated to be 8 , three orders of magnitude smaller than the $K_{\mathrm{d}}$ of Cs $\left(4 \times 10^{3}\right)$, supports the idea that Cs was preferentially removed (IAEA, 2004).

\subsection{Distributions of other radionuclides in the sediments}

We also detected the following nuclides in the sediments: ${ }^{95} \mathrm{Nb} \quad\left(t_{1 / 2}=35\right.$ days $),{ }^{110 \mathrm{~m}} \mathrm{Ag} \quad\left(t_{1 / 2}=250\right.$ days $)$, ${ }^{129} \mathrm{Te} \quad\left(t_{1 / 2}=69.6 \mathrm{~min}\right),{ }^{129 \mathrm{~m}} \mathrm{Te}\left(t_{1 / 2}=33.6\right.$ days $), \quad$ and ${ }^{125} \mathrm{Sb}\left(t_{1 / 2}=2.8 \mathrm{yr}\right)$. Their concentrations and activity ratios 


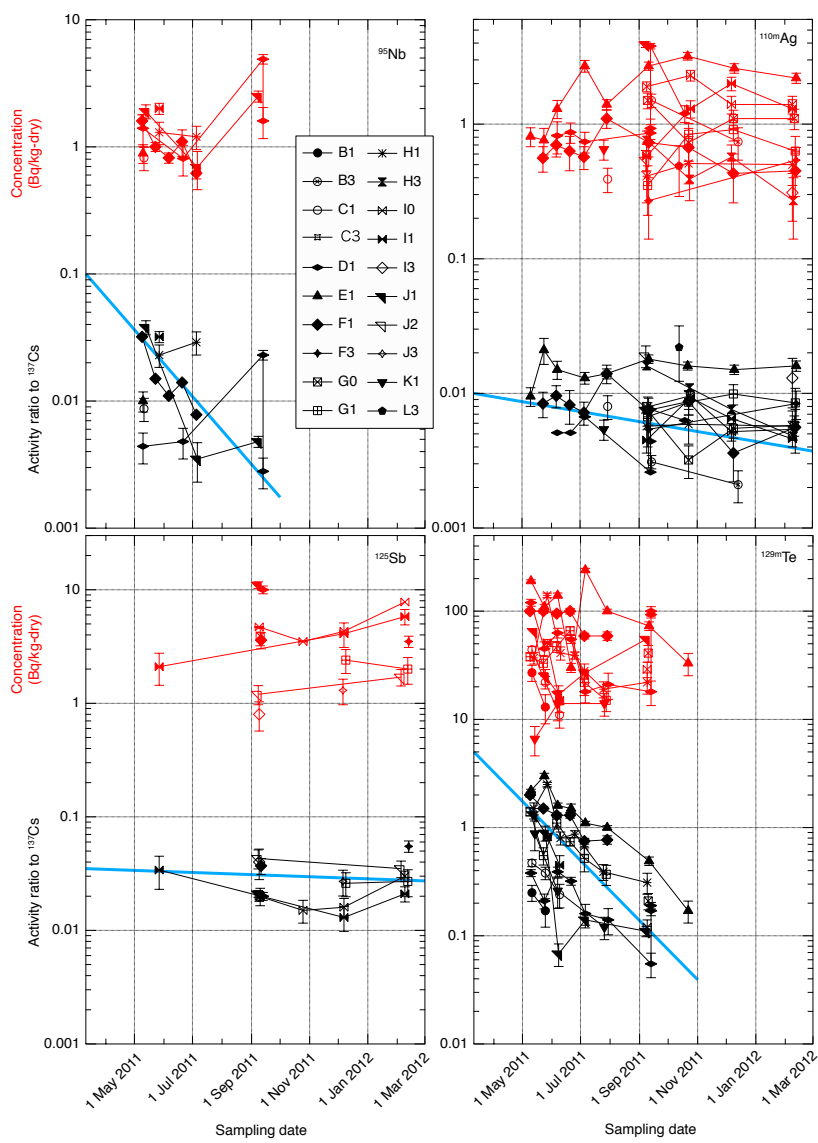

Fig. 13. Temporal variations of ${ }^{95} \mathrm{Nb},{ }^{110 \mathrm{~m}} \mathrm{Ag},{ }^{125} \mathrm{Sb}$, and ${ }^{129} \mathrm{~m}_{\mathrm{Te}}$ concentrations (red symbols) and their corresponding ${ }^{137} \mathrm{Cs}$ activity ratios (black symbols) in sediments. The blue lines indicate theoretical decay curves for the nuclides at arbitrary initial values.

with respect to ${ }^{137} \mathrm{Cs}$ are plotted in Fig. 13. Because ${ }^{129 \mathrm{~m}} \mathrm{Te}$ $\left(t_{1 / 2}=33.6\right.$ days $)$ has a shorter-lived progeny nuclide, ${ }^{129} \mathrm{Te}$ $\left(t_{1 / 2}=69.6 \mathrm{~min}\right)$, the two nuclides should have been in radioactive equilibrium in the sediments. We calculated an average ${ }^{129 \mathrm{~m}} \mathrm{Te} /{ }^{129} \mathrm{Te}$ activity ratio of $0.68 \pm 0.14$, which agreed well with the isomeric transition rate of ${ }^{129 \mathrm{~m}} \mathrm{Te}$ relative to that of ${ }^{129} \mathrm{Te}, 0.647$. Accordingly, the variation patterns of the two nuclides were almost identical to each other.

The concentrations of the nuclides plotted in Fig. 13 varied significantly among the sampling stations. In addition, the temporal variation of the activity ratios relative to ${ }^{137} \mathrm{Cs}$, especially those of ${ }^{95} \mathrm{Nb}$ and ${ }^{110 \mathrm{~m}} \mathrm{Ag}$, did not necessarily agree with the theoretical decay curves indicated by the blue lines in Fig. 13. Differences in the behaviors of radionuclides in the marine environment may be one of the reasons for the change of ratio. They do not, however, fully account for the variations of both the concentration and their ratios in the sediments. Furthermore, when the ratios were decaycorrected to 11 March 2011, the calculated ratios were scattered over an order of magnitude range. Variable activity ratios for Fukushima-derived radionuclides in soil have been reported (e.g., Watanabe et al., 2012; Yoshida and Takahashi, 2012). These investigators ascribed the variability to the variable initial ratios at the accident site.

The activity ratios of ${ }^{95} \mathrm{Nb},{ }^{110 \mathrm{~m}} \mathrm{Ag},{ }^{129} \mathrm{Te},{ }^{129 \mathrm{~m}} \mathrm{Te}$, and ${ }^{125} \mathrm{Sb}$ to ${ }^{137} \mathrm{Cs}$ calculated for the samples from Stn. D1 collected on 13 September 2011 also varied greatly. The complexity of their spatiotemporal variations in the sediments may have been due to temporal changes of the activity ratios from the FDNPP and the fluctuating pathways by which these nuclides reached the sediments. As mentioned above for ${ }^{131} \mathrm{I}$, this hypothesis is valid only if the nuclides stayed in the seawater for a short time.

\section{Conclusions}

The distributions of anthropogenic radionuclides in surface sediments collected from the Pacific Ocean off Fukushima Prefecture were complicated, reflecting variability in the characteristics of the bottom sediments and variability in the nuclide concentrations in the overlying water. Except for ${ }^{90} \mathrm{Sr}$, rapid removal of the nuclides from seawater to the sediments also contributed to the variations in their distributions. The mechanism by which the radionuclides were incorporated into the sediments has yet to be elucidated fully. Biological activity may have played an important role, and the unusual sedimentary environment resulting from the huge suspended load carried back from the land by the tsunami of March 2011 may have led to rapid removal of the nuclides from seawater.

The fate of the nuclides in sediments is of great concern to the people of Japan and to the global community. Because nuclide concentrations in seawater have been decreasing, deposition from seawater may no longer be significant, unless there are additional releases from the nuclear plant or increased riverine inputs derived from decontamination on land. However, even though the inventories of radionuclides in the sediments seem to be slightly decreasing, the remaining nuclides will not disappear quickly. Continuous, thorough monitoring and detailed research studies on the behavior of the radionuclides in sediments for many years to come are required.

\section{Supplementary material related to this article is available online at: http://www.biogeosciences.net/10/ 5019/2013/bg-10-5019-2013-supplement.zip.}

Acknowledgements. We sincerely thank our colleagues at the Marine Ecology Research Institute for their help with sampling and for logistical support for the monitoring program. We also acknowledge the crews of the research vessels and technicians from Nippon Kaiyo Co. who assisted greatly with fieldwork onboard the ships. This research was conducted under contract with MEXT.

Edited by: K. Buesseler 


\section{References}

Ambe, D., Kaeriyama, H., Shigenobu, Y., Fujimoto, K., Ono, T., Setou, T., and Watanabe, T.: Distribution of radioactive cesium in sea sediment and bottom boundary layer associated with the Fukushima Daiichi Nuclear Power Plant accident, 23th Ocean Engineering Symposium, JFOES/JASNAOE, 1-6, 2012 (in Japanese with English abstract).

Aoyagi, K. and Igarashi, S.: On the size distribution of sediments in the coastal sea of Fukushima Prefecture. Bull. Fukushima Pref. Fish. Exp. Stat., 8, 69-81, 1999 (in Japanese).

Aoyama, M., Tsumune, D., Uematsu, M., Kondo, F., and Hamajima, Y.: Temporal variation of ${ }^{134} \mathrm{Cs}$ and ${ }^{137} \mathrm{Cs}$ activities in surface water at stations along the coastline near the Fukushima Daiichi Nuclear Power Plant accident site, Japan. Geochem. J., 46, 321-325, 2012.

Bailly du Bois, P., Laguionie, P., Boust, D., Korsakissok, I., Didier, D., and Fievet, B.: Estimation of marine source-term following Fukushima Dai-ichi accident, J. Environ. Radioactiv., 114, 2-9, 2012.

Børrentzen, P. and Salbu, B.: Fixation of Cs to marine sediments estimated by a stochastic modeling approach, J. Environ. Radioact., 61, 1-20, 2002.

Buesseler, K. O., Jayne, S. R., Fisher, N. S., Rypina, I. I., Baumann, H., Baumann, Z., Breier, C. F., Douglass, E. M., George, J., Macdonald, A. M., Miyamoto, H., Nishikawa, J., Pike, S. M., and Yoshida, S.: Fukushima-derived radionuclides in the ocean and biota off Japan, P. Natl. Acad. Sci., 109, 5984-5988, 2012.

Chino, M., Nakayama, H., Nagai, H., Terada, H., Katata, G., and Yamazawa, H.: Preliminary estimation of release amounts of ${ }^{131} \mathrm{I}$ and ${ }^{137} \mathrm{Cs}$ accidentally discharged from the Fukushima Daiichi Nuclear Power Plant into the atmosphere, J. Nucl. Sci. Technol., 48, 1129-1134, 2011.

Fowler, S. W., Buat-Menard, P., Yokoyama, Y., Ballestra, S., Holm, E., and Nguyen, H. V.: Rapid removal of Chernobyl fallout from Mediterranean surface waters by biological activity, Nature, 329, 56-58, 1987.

IAEA: Sediment distribution coefficients and concentration factors for biota in the marine environment, Tech. Rep. Ser. No. 422, 2004.

IRSN: Impact on marine environment of radioactive releases resulting from the Fukushima-Daiichi nuclear accident. Institut de Radioprotection et de Sûreté Nucléaire, 9 pp., www.irsn.fr/EN/ news/Pages/201103_seism-in-japan.aspx, 2011.

Kawamura, H., Kobayashi, T., Furuno, A., In, T., Ishikawa, Y., Nakayama, T., Shima, S., and Awaji, T.: Preliminary numerical experiments on oceanic dispersion of ${ }^{131} \mathrm{I}$ and ${ }^{137} \mathrm{Cs}$ discharged into the ocean because of the Fukushima Daiichi Nuclear Power Plant disaster, J. Nucl. Sci. Technol., 48, 1349-1356, 2011.
Kusakabe, M. Ku, T. L., Harada, K., Taguchi, K., and Tsunogai, S.: Chernobyl radioactivity found in mid-water sediment trap interceptor in the N. Pacific and Bering Sea, Geophys. Res. Lett., 15, 44-47, 1988.

Masumoto, Y., Miyazawa, Y., Tsumune, D., Tsubono, T., Kobayashi, T., Kawamura, H., Estournel, C., Marsaleix, P., Lanerolle, L., Mehra, A., and Garraffo, Z. D.: ${ }^{137}$ Cs Released from the Fukushima Daiichi Nuclear Power Plant, Elements, 8, 207-212, 2012.

MEXT: Radioactivity measurement; Series No. 2, (http://www. kankyo-hoshano.go.jp/series/lib/No2.pdf), 2002 (in Japanese).

MEXT, Report of comprehensive monitoring program for radioactivity in the marine environments, 2010, 2011 (in Japanese).

MEXT, Report of comprehensive monitoring program for radioactivity in the marine environments, 2011, 2012 (in Japanese).

Oikawa, S., Takata, H., Watabe, T., Misonoo, J., and Kusakabe, M.: Distribution of the Fukushima-derived radionuclides in seawater in the Pacific off the coast of Miyagi, Fukushima, and Ibaraki Prefectures, Japan, Biogeosciences, 10, 5031-5047, doi:10.5194/bg-10-5031-2013, 2013.

Otosaka, S. and Kobayashi, T.: Sedimentation and remobilization of radiocesium in the coastal area of Ibaraki, $70 \mathrm{~km}$ south of the Fukushima Dai-ichi Nuclear Power Plant, Environ. Monit. Assess., 185, 5419-5433, doi:10.1007/s10661-012-2956-7, 2012.

Qin, H., Yokoyama, Y., Fan, Q., Iwatani, H., Tanaka, K., Sakaguchi, A., Kanai, Y., Zhu, J., Onda, Y., and Takahashi, Y.: Investigation of cesium adsorption on soil and sediment samples from Fukushima Prefecture by sequential extraction and EXAFS technique, Geochem. J., 46, 297-302, 2012.

Tsukada, H., Takeda, A., Hisamatsu, S., and Inaba, J.: Concentration and specific activity of fallout ${ }^{137} \mathrm{Cs}$ in extracted and particle-size fractions of cultivated soils, J. Environ. Radioact., 99, 875-881, 2008.

Tsumune, D., Tsubono, T., Aoyama, M., and Hirose, K.: Distribution of oceanic ${ }^{137} \mathrm{Cs}$ from the Fukushima Dai-ichi Nuclear Power Plant simulated numerically by a regional ocean model, J. Environ. Radioactiv., 111, 100-108, 2012.

Watanabe, T., Tsuchiya, N., Oura, Y., Ebihara, M., Inoue, C., Hirano, N., Yamada, R., Yamasaki, S., Okamoto, A., Nara, F. W., and Nunohara, K.: Distribution of artificial radionuclides $\left({ }^{110} \mathrm{~m} \mathrm{Ag},{ }^{129} \mathrm{~m} \mathrm{Te},{ }^{134} \mathrm{Cs},{ }^{137} \mathrm{Cs}\right)$ in surface soils from Miyagi Prefecture, northeast Japan, following the 2011 Fukushima Daiichi Nuclear Power Plant accident, Geochem. J., 46, 279-285, 2012.

Yoshida, N. and Takahashi, Y.: Land-surface contamination by radionuclides from the Fukushima Daiichi Nuclear Power Plant accident, Elements, 8, 201-206, 2012. 